\title{
Source rupture processes of the 2016 Kumamoto, Japan, earthquakes estimated from strong-motion waveforms
}

\author{
Hisahiko Kubo ${ }^{1 *} \mathbb{D}$, Wataru Suzuki ${ }^{1}$, Shin Aoi ${ }^{1}$ and Haruko Sekiguchi ${ }^{2}$
}

\begin{abstract}
The detailed source rupture process of the M 7.3 event (April 16, 2016, 01:25, JST) of the 2016 Kumamoto, Japan, earthquakes was derived from strong-motion waveforms using multiple-time-window linear waveform inversion. Based on the observations of surface ruptures, the spatial distribution of aftershocks, and the geodetic data, a realistic curved fault model was developed for source-process analysis of this event. The seismic moment and maximum slip were estimated as $5.5 \times 10^{19} \mathrm{Nm}\left(M_{\mathrm{w}} 7.1\right)$ and $3.8 \mathrm{~m}$, respectively. The source model of the $M 7.3$ event had two significant ruptures. One rupture propagated toward the northeastern shallow region at $4 \mathrm{~s}$ after rupture initiation and continued with large slips to approximately $16 \mathrm{~s}$. This rupture caused a large slip region 10-30 km northeast of the hypocenter that reached the caldera of Mt. Aso. Another rupture propagated toward the surface from the hypocenter at 2-6 s and then propagated toward the northeast along the near surface at 6-10 s. A comparison with the result of using a single fault plane model demonstrated that the use of the curved fault model led to improved waveform fit at the stations south of the fault. The source process of the M 6.5 event (April 14, 2016, 21:26, JST) was also estimated. In the source model obtained for the $M 6.5$ event, the seismic moment was $1.7 \times 10^{18} \mathrm{Nm}\left(M_{w} 6.1\right)$, and the rupture with large slips propagated from the hypocenter to the surface along the north-northeast direction at 1-6 s. The results in this study are consistent with observations of the surface ruptures.
\end{abstract}

Keywords: The 2016 Kumamoto earthquakes, Source rupture process, Strong-motion waveforms

\section{Introduction}

A series of earthquakes in Kumamoto and Oita Prefectures, central Kyushu, Japan, from April 14, 2016, collectively referred to as the 2016 Kumamoto earthquakes, caused damage by strong ground motions, surface ruptures, and subsequent landslides: more than 100 people were killed, more than 2000 people were injured, and more than 38,000 houses were fully or partially destroyed (FDMA 2016). The events occurred mainly within the Hinagu and Futagawa fault zones (Fig. 1), which are known to be active faults. The Hinagu fault zone consists of the Takano-Shirohata segment, the Hinagu segment, and the Yatsushirokai segment, while the Futagawa

\footnotetext{
*Correspondence: hkubo@bosai.go.jp

${ }^{1}$ National Research, Institute for Earth Science and Disaster Resilience,

3-1, Tennodai, Tsukuba, Ibaraki 305-0006, Japan

Full list of author information is available at the end of the article
}

fault zone consists of the Futagawa segment, the Uto segment, and the north coast of Uto Peninsula segment (ERC/HERP 2013). The National Research Institute for Earth Science and Disaster Resilience (NIED) deploys and operates two nationwide strong-motion networks, K-NET and KiK-net (Aoi et al. 2011). These networks successfully recorded the strong ground motions of the 2016 Kumamoto earthquakes. In this study, using the strong-motion records, we estimate source rupture processes of large events of the 2016 Kumamoto earthquakes to reveal the detailed fault rupture process and the mechanism for generating strong ground motions. The results will be useful for updating the source modeling of crustal earthquakes for improved quantitative strong ground motion prediction.

The main target of this study is the $M_{\mathrm{JMA}} 7.3$ event (hereafter called the $M 7.3$ event) that occurred at 01:25 JST on April 16, 2016 (16:25 UTC on April 15, 2016). 


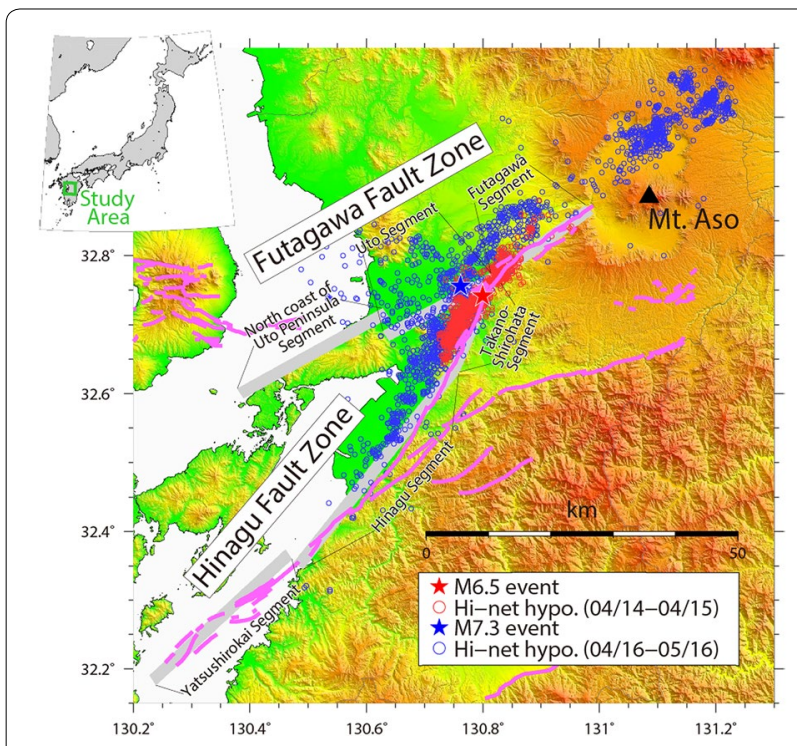

Fig. 1 Map of the study area. Red and blue stars denote the hypocenters of the M 6.5 event (April 14, 2016, 21:26 JST) and the M 7.3 event (April 16, 2016, 01:25 JST), respectively. Red circles denote the hypocenters of events $(M \geq 1)$ in the period between the $M 6.5$ event and the $M 7.3$ event, which were determined by the NIED Hi-net. Blue circles denote the hypocenters of aftershocks $(M \geq 1) 1$ month after the $M 7.3$ event, as determined by the NIED Hi-net. Violet lines denote the surface traces of active faults (AIST 2007). Gray lines denote the rough locations of the Hinagu fault zone (Takano-Shirohata segment, Hinagu segment, and Yatsushirokai segment) and the Futagawa fault zone (Futagawa segment, Uto segment, and north coast of Uto Peninsula segment) (ERC/HERP 2013)

This event caused strong ground motions that were felt throughout Kyushu, with maximum seismic intensity of 7, the largest intensity on the Japan Meteorological Agency (JMA) scale, and maximum peak ground acceleration (PGA) over $1000 \mathrm{~cm} / \mathrm{s}^{2}$. The observations of surface ruptures, the spatial distribution of aftershocks, and the geodetic data, which will be mentioned later, suggest that the rupture of this event occurred on multiple fault planes along the Hinagu and Futagawa fault zones. Therefore, the use of a single fault plane model, which has been adopted in many source-process analyses, is unsuitable to analyze the source process of this event and a more realistic fault model needs to be used. In this study, we propose a curved fault model based on the observations of surface ruptures, the spatial distribution of aftershocks, and the geodetic data. Using the curved fault model, we estimate the source process of the $M 7.3$ event and compare it with the hypocenter distribution of aftershocks, the distribution of observed surface ruptures, and the result of back-projection analysis with high-frequency seismic waves. We also check the contribution of the fault ruptures to the strong ground motions. In addition, we conduct another source inversion with a single fault plane model to demonstrate the significance of using the curved fault model by comparing their results.

We also estimate the source process of the first large event $\left(M_{\mathrm{JMA}} 6.5\right.$; hereafter called the $M 6.5$ event) that occurred at 21:26 JST on April 14, 2016 (12:26 UTC on April 14, 2016), and caused strong ground motions with maximum seismic intensity of 7 and maximum PGA over $1000 \mathrm{~cm} / \mathrm{s}^{2}$. We compare the source model with the hypocenter distribution of events between the $M 6.5$ event and the $M 7.3$ event and the distribution of seismicity in 2000. We also discuss the relationship between the fault rupture and the strong ground motions.

\section{The M 7.3 event (April 16, 2016, 01:25, JST) Curved fault model}

The seismicity of the 2016 Kumamoto earthquakes occurred mainly in three regions: the Kumamoto region, the region north of $\mathrm{Mt}$. Aso, and the Oita region. In the Kumamoto region, the events in the period between the $M 6.5$ event and the $M 7.3$ event occurred mainly along the Hinagu fault zone, which has a length of approximately $25 \mathrm{~km}$ (Fig. 1). After the $M 7.3$ event, the seismicity extended to the Futagawa fault zone and to the southern extension of the seismicity before the $M 7.3$ event. The epicenters extended over approximately $50 \mathrm{~km}$. Around the epicenter of the $M 7.3$ event, the events after the $M$ 7.3 event occurred mainly west of the high-seismicity area before the $M 7.3$ event. This observation implies that the source area of the $M 7.3$ event spread over the Hinagu and Futagawa fault zones. After the $M 7.3$ event, various groups conducted field surveys of surface ruptures (e.g., GSJ/AIST 2016; Kumahara et al. 2016; Shirahama et al. 2016). The surveys revealed surface ruptures along the known surface traces of the Hinagu and Futagawa fault zones. The surface ruptures have extended approximately $30 \mathrm{~km}$ and almost reached the caldera of Mt. Aso. Surface displacements were also recorded by GNSS Earth Observation Network System (GEONET) and ALOS-2/ PALSAR-2 interferometric SAR (InSAR) (e.g., Ozawa et al. 2016; Yarai et al. 2016). The geodetic data indicate that right-lateral fault motion occurred along the Hinagu and Futagawa fault zones during the $M 7.3$ event. The data also indicate that the rupture also occurred on the eastern extension of the Futagawa fault zone. Thus, these observations clearly indicate that the rupture of the $M 7.3$ event occurred on multiple fault planes along the Hinagu fault zone, the Futagawa fault zone, and its eastern extension. Therefore, rather than a single fault model, we chose to use a more realistic fault model to analyze the source process of this earthquake. Because the hypocenter distribution of aftershocks did not have a sharp structure, such as a step, and the strike of the surface ruptures inferred from the field surveys and InSAR 
data changes continuously, we developed a curved fault model of the $M 7.3$ event (Fig. 2a). This curved fault model consists of multiple planes, each with a width of $24 \mathrm{~km}$ and a common top depth (approximately $1 \mathrm{~km}$ ). These planes are grouped into three major parts (north, central, and south) with transitional parts that smoothly connect the major parts. The strike angle and top location of each part follow Ozawa et al. (2016). They identified a discontinuity of slant-range change of InSAR data along the Futagawa fault zone and a steep gradient of slant-range change along both the Hinagu fault zone and the eastern extension of the Futagawa fault zone (Fig. 2b). The dip angles of the central and south parts were based on the hypocenter distribution of aftershocks (Fig. 2c); the dip angle $\left(74^{\circ}\right)$ in the south part is steeper than that $\left(65^{\circ}\right)$ in the central part. The extensions to the surface are spatially consistent with the observed surface ruptures. We set the rupture starting point, included in the south part, at the hypocenter location, $32.7557^{\circ} \mathrm{N}, 130.7616^{\circ} \mathrm{E}$, and depth of $13.58 \mathrm{~km}$, obtained by the double-difference method (Waldhauser and Ellsworth 2000) in the same procedure as used in Yano and Matsubara (2016). The dip angle in the north part was set to $75^{\circ}$ considering the fit between the assumed fault model and the hypocenter distribution of aftershocks north of Mt. Aso (Fig. 2c) and the continuity from the central part. The top length of the curved fault model was approximately $53 \mathrm{~km}$. The proposed fault model corresponds to the Takano-Shirohata segment of the Hinagu fault zone, the Futagawa segment of the Futagawa fault zone, and its eastern extension.
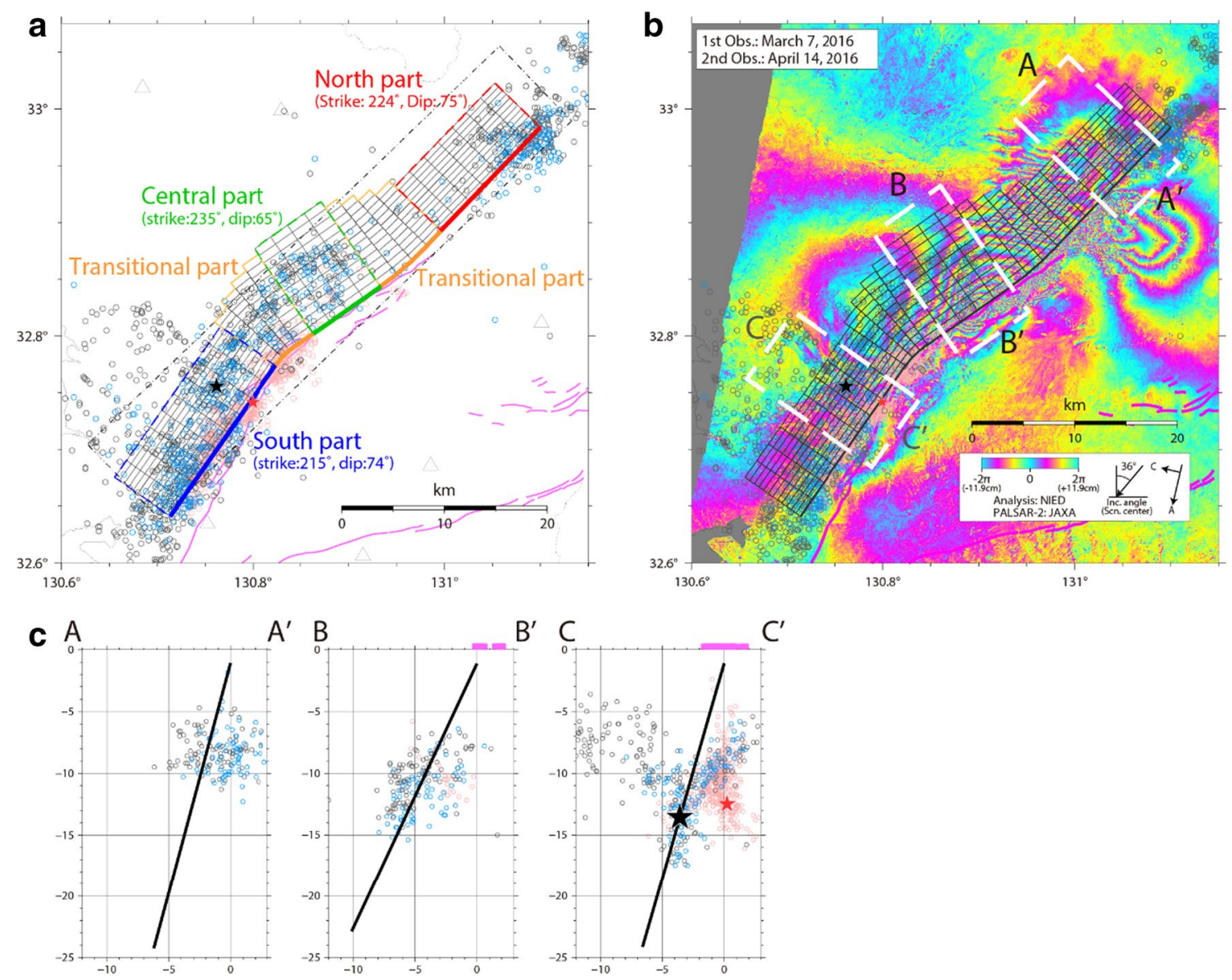

Fig. 2 a Map view of curved fault model for the M 7.3 event, which is composed of three major parts (north, central, and south) with two transitional parts that smoothly connect the major parts. Black and red stars denote the hypocenter of the $M 7.3$ and $M 6.5$ events, respectively. Sky blue and gray circles denote the hypocenters of aftershocks $(M \geq 1)$, which were determined by the NIED Hi-net, 1 day and 1 month after the $M 7.3$ event, respectively. Pink circles denote the hypocenters of events $(M \geq 1)$ in the period between the $M 6.5$ event and the $M 7.3$ event, as determined by the NIED Hi-net. The broken line denotes an additional fault model for the $M 7.3$ event that has a $56 \mathrm{~km} \times 24 \mathrm{~km}$ rectangular plane with a strike of $224^{\circ}$ and a dip of $65^{\circ}$. b Curved fault model for the $M 7.3$ event with mosaicked SAR interferograms made by comparing two SAR images before and after the M 7.3 event (Ozawa et al. 2016). c Cross sections for the regions A, B, and C shown in Fig. 2b. Black thick lines denote the fault model for the M 7.3 event 


\section{Method and data}

The source process is estimated by the multi-time-window linear waveform inversion method (Olson and Apsel 1982; Hartzell and Heaton 1983), which has been applied to source-process analyses of many earthquakes (e.g., Sekiguchi et al. 2000; Suzuki et al. 2010). For a detailed description of the methodology employed, we refer the reader to the aforementioned studies. The curved fault model is divided into 28 subfaults along the strike direction and 12 subfaults along the dip direction, each with a size of approximately $2 \mathrm{~km} \times 2 \mathrm{~km}$ (Fig. 2a). The slip time history of each subfault is represented by 13 time windows, each with a width of $0.8 \mathrm{~s}$, with a lag of 0.4-s lag. Thus, the allowed slip duration for each subfault is $5.6 \mathrm{~s}$. The first time window starting time is defined as the time prescribed by a circular rupture propagation with the constant speed of $V_{\mathrm{ftw}}$. The slip rate of each time window at each subfault is derived by minimizing the difference between the observed and synthetic waveforms normalized for each station by the observed maximum amplitude of the three components. To stabilize the inversion, the slip angle is allowed to vary within $\pm 45^{\circ}$ around the central rake angle using the nonnegative least-squares scheme (Lawson and Hanson 1974). The central rake angle is set to $-142^{\circ}$, which is the rake angle of the F-net moment tensor solution (Fukuyama et al. 1998). In addition, a spatiotemporal smoothing constraint on the slip (Sekiguchi et al. 2000) is imposed. We performed inversions using several combinations of $V_{\mathrm{ftw}}$ and weight of smoothing constraint. The weight of the smoothing constraint for inversion with a certain $V_{\mathrm{ftw}}$ value is determined based on Akaike's Bayesian information criterion (Akaike 1980) following previous studies (e.g., Sekiguchi et al. 2000), and the inversion solution that gives the minimum misfit among those with different $V_{\mathrm{ftw}}$ is selected as the best model.

We use three-component strong-motion waveforms at 27 stations within an epicenter distance of approximately $100 \mathrm{~km}$ : 13 K-NET stations with ground surface observation, $9 \mathrm{KiK}$-net stations with borehole observation, 2 KiK-net stations with ground surface observation, and 3 F-net (Okada et al. 2004) stations with observation in a vault (Fig. 3a). Although at most KiK-net stations we use the data recorded by seismograph in borehole, we use the data recorded by seismograph on surface at the two KiK-net stations because seismographs in borehole were broken at the stations. At the F-net stations, we use the data recorded by the velocity-type strong-motion seismographs. Except for the F-net stations whose original data are velocity waveforms, the observed acceleration waveforms are numerically integrated in time domain into velocity. The velocity waveforms are band-pass filtered between 0.05 and $1.0 \mathrm{~Hz}$ and resampled to $5 \mathrm{~Hz}$. The time length of the dataset is $30 \mathrm{~s}$ (starting from $1 \mathrm{~s}$ before the $\mathrm{S}$-wave arrival, which is carefully identified by visual inspection). Green's functions are calculated with the discrete wave number method (Bouchon 1981) and the reflection/transmission matrix method (Kennett and Kerry 1979) assuming a 1D velocity structure model. The velocity structure model of each station is adapted from the structure just beneath the station given by a 3D subsurface structure model of the whole of Japan (Fujiwara
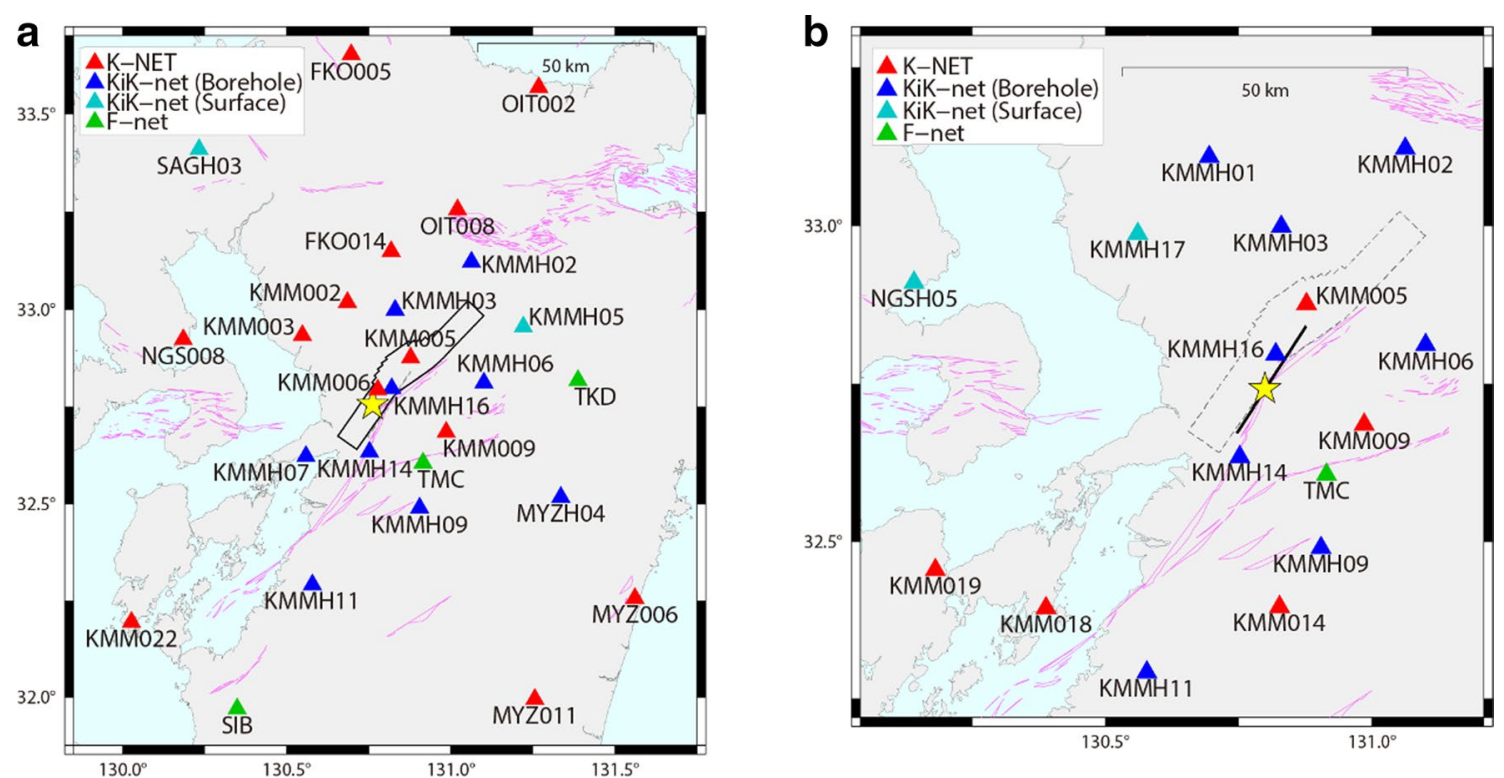

Fig. 3 Station distribution and fault model for $\mathbf{a}$ the $M 7.3$ event and $\mathbf{b}$ the $M$ G.5 event. The star denotes the epicenter for each event 


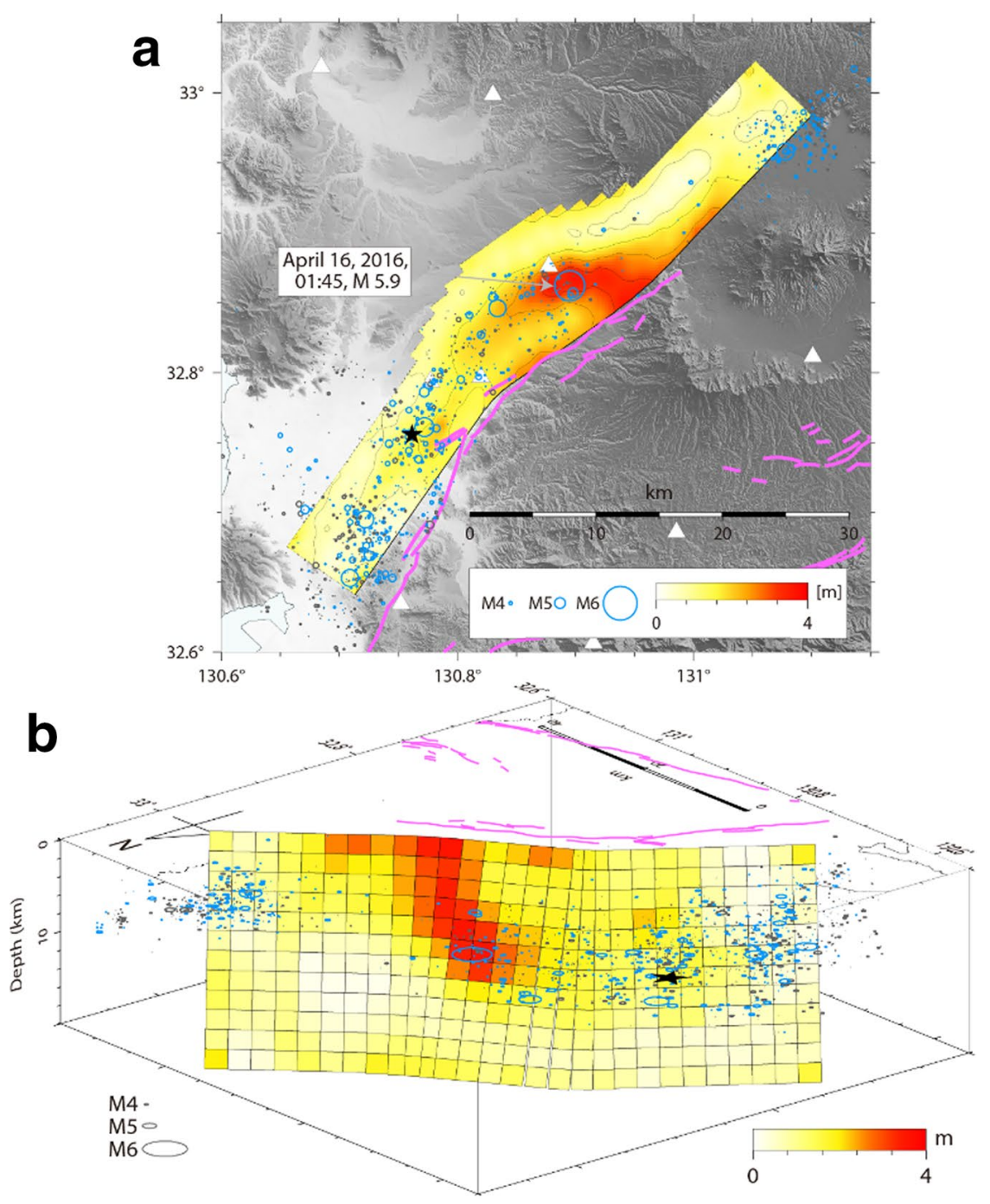

C Distance along strike on top of curved fault model ( $\mathrm{km})$

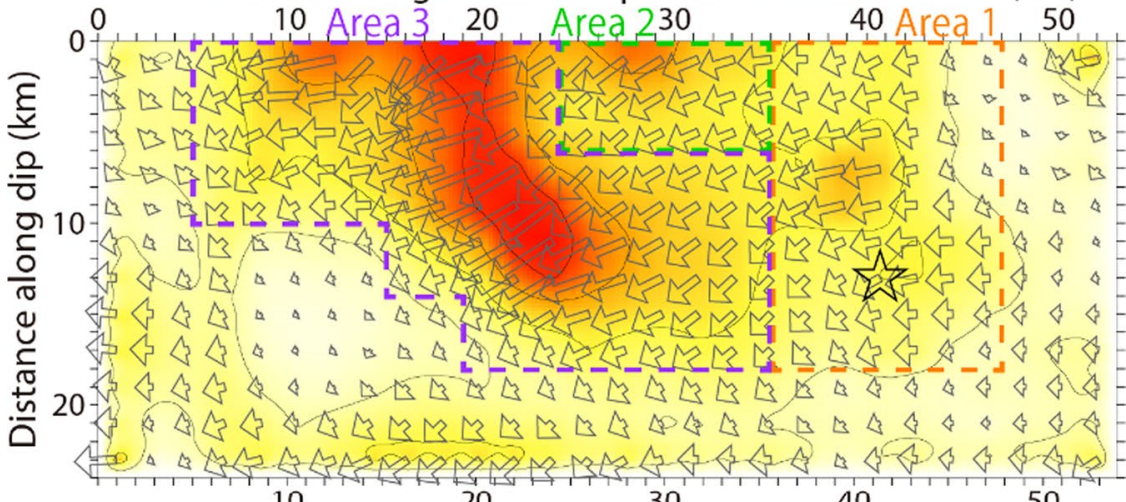

Distance along strike on bottom of curved fault model $(\mathrm{km})$

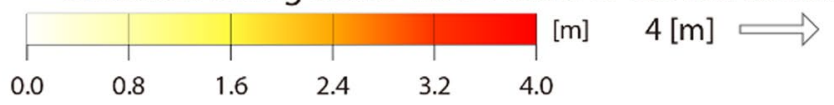


(See figure on previous page.)

Fig. 4 a Map projection of the total slip distribution for the $M 7.3$ event. Slip contour interval is $0.8 \mathrm{~m}$. The star denotes the rupture starting point. Sky blue and gray circles denote the hypocenters of aftershocks $(M \geq 1) 1$ day and 1 month after the $M 7.3$ event, respectively, which were determined by the NIED Hi-net. Circle sizes indicate event magnitudes. Open triangles denote stations used in the analysis. b Perspective illustration of the total slip distribution (azimuth: $310^{\circ}$, elevation: $2^{\circ}$ ). $\mathbf{c}$ Planar projection of the total slip distribution. The vectors denote the direction and the amount of the slip of the hanging wall side. The rectangles with orange, green, and purple broken lines indicate the areas with large slips defined in this study, i.e., Areas 1, 2, and 3, respectively

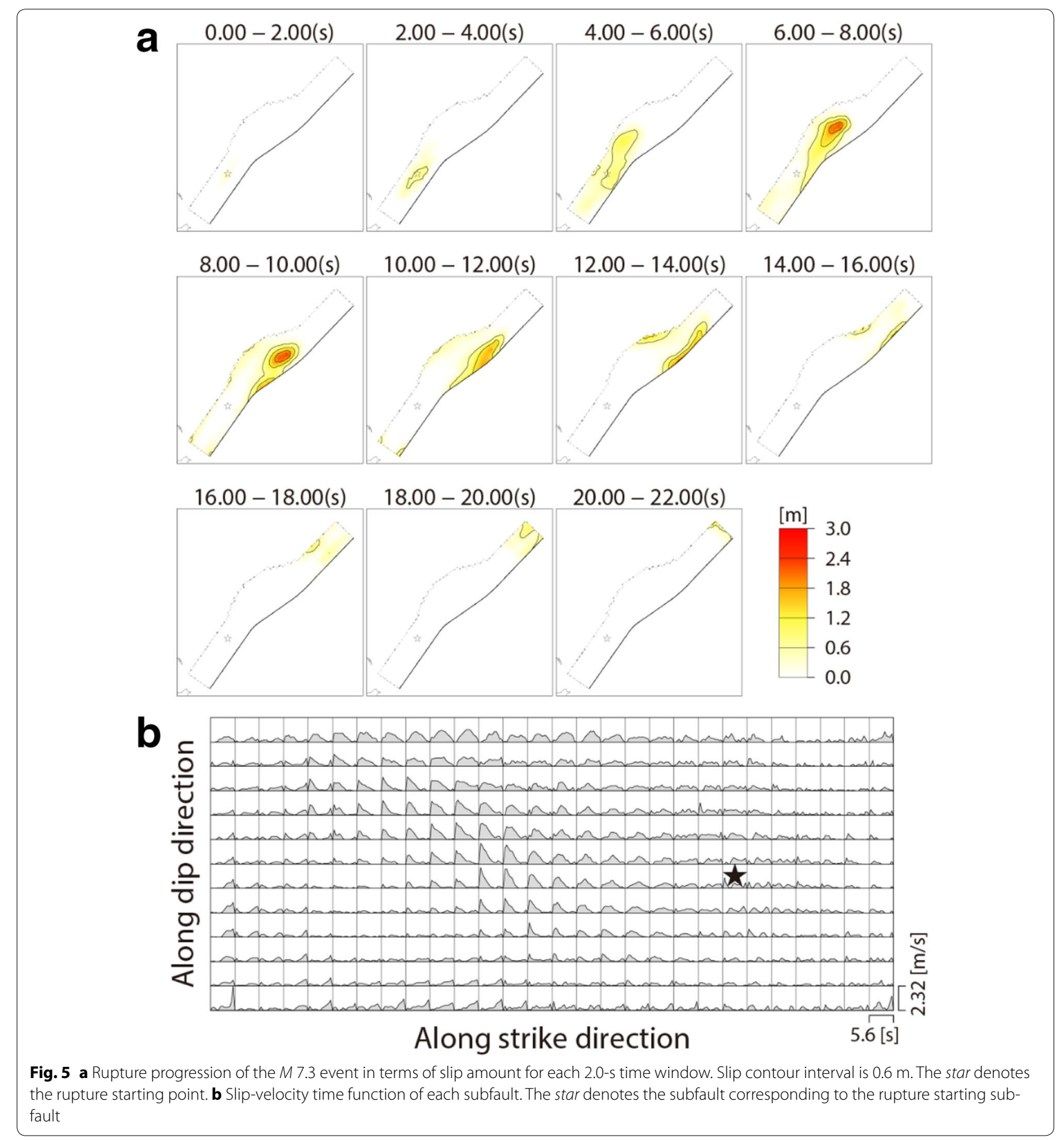




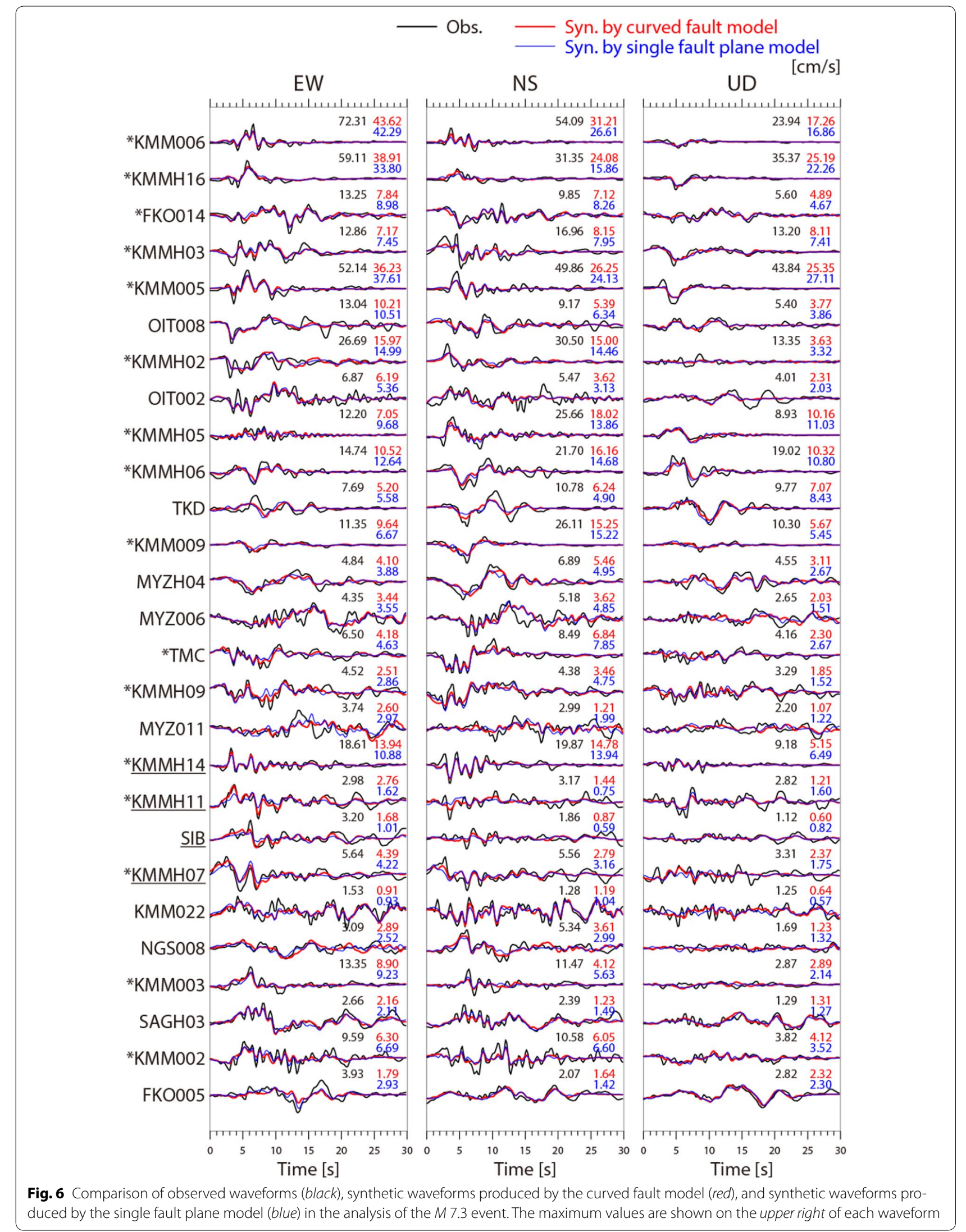




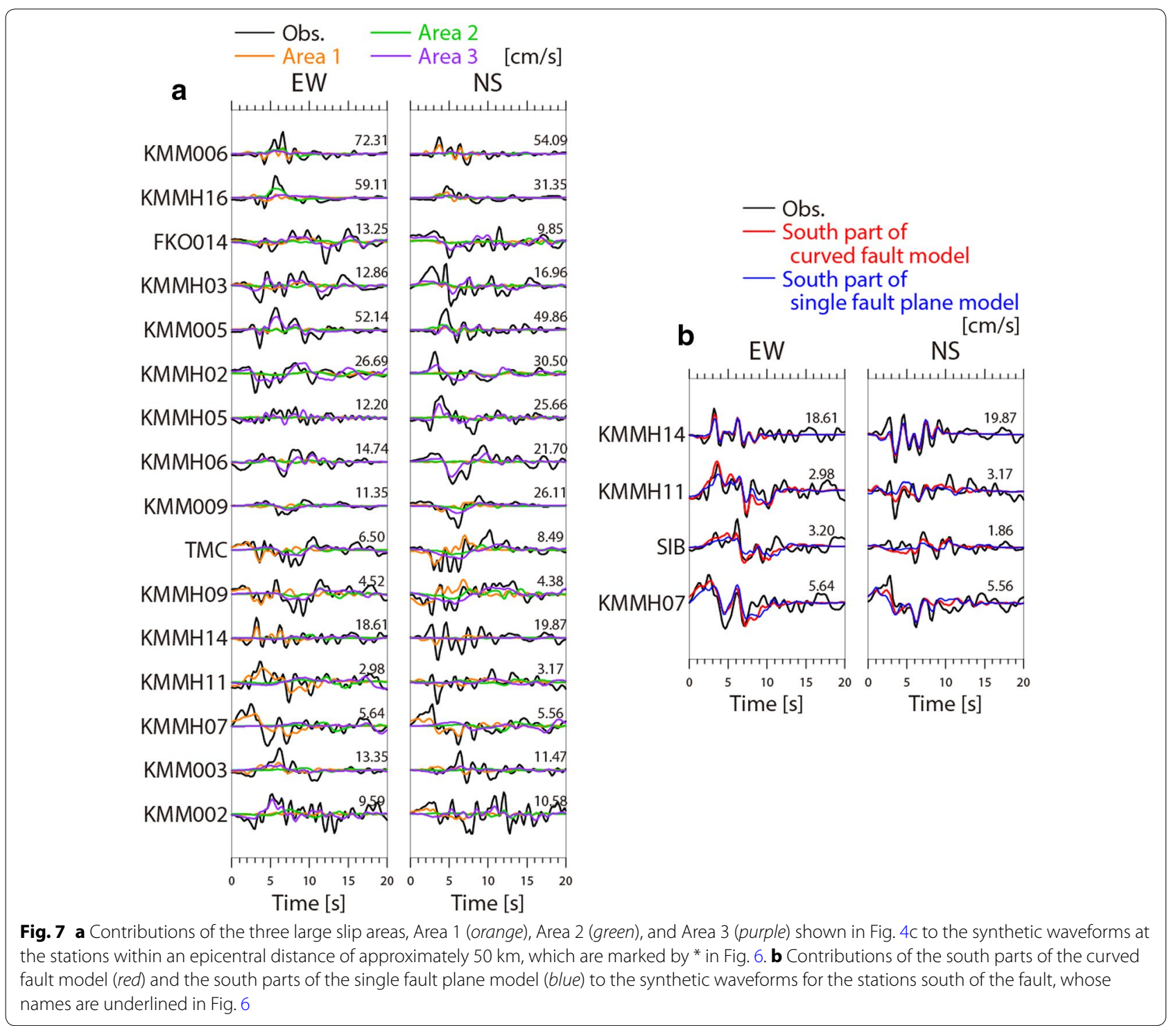

et al. 2009) and a logging profile of the station provided by NIED on the KiK-net Web site. To consider the rupture propagation effect inside each subfault, 25 point sources are distributed uniformly over each subfault in the calculation of Green's functions (e.g., Wald et al. 1991). For the stations near the fault (KMMH16, KMM006, KMM005, and KMMH14), we use weights that are two times larger than those for the other stations.

\section{Source process of the $M 7.3$ event}

Figure 4 shows the estimated total slip distribution of the $M 7.3$ event by map projection (Fig. 4a), perspective illustration (Fig. 4b), and planar projection (Fig. 4c). Figure 5 shows the rupture progression and the slipvelocity time function of each subfault. The seismic moment and maximum slip are $5.5 \times 10^{19} \mathrm{Nm}\left(M_{\mathrm{w}} 7.1\right)$ and $3.8 \mathrm{~m}$, respectively. $V_{\mathrm{ftw}}$ is $2.6 \mathrm{~km} / \mathrm{s}$, which gives the smallest misfit solution among the solutions obtained using $V_{\mathrm{ftw}}$ ranging from 1.8 to $3.8 \mathrm{~km} / \mathrm{s}$. Large slips $(>2.4 \mathrm{~m})$ are found $10-30 \mathrm{~km}$ northeast of the rupture starting point and are distributed from the depth of approximately $15 \mathrm{~km}$ to the top of the fault model. The large slip region is located on the Futagawa segment of the Futagawa fault zone and its eastern extension, and the northeastern edge reaches the northwestern part of the caldera of Mt. Aso. These large slips were caused by the main rupture at 4-16 $\mathrm{s}$ after rupture initiation. The rupture first propagated at the depth of $10-15 \mathrm{~km}$ toward the northeast and then propagated toward the surface. 

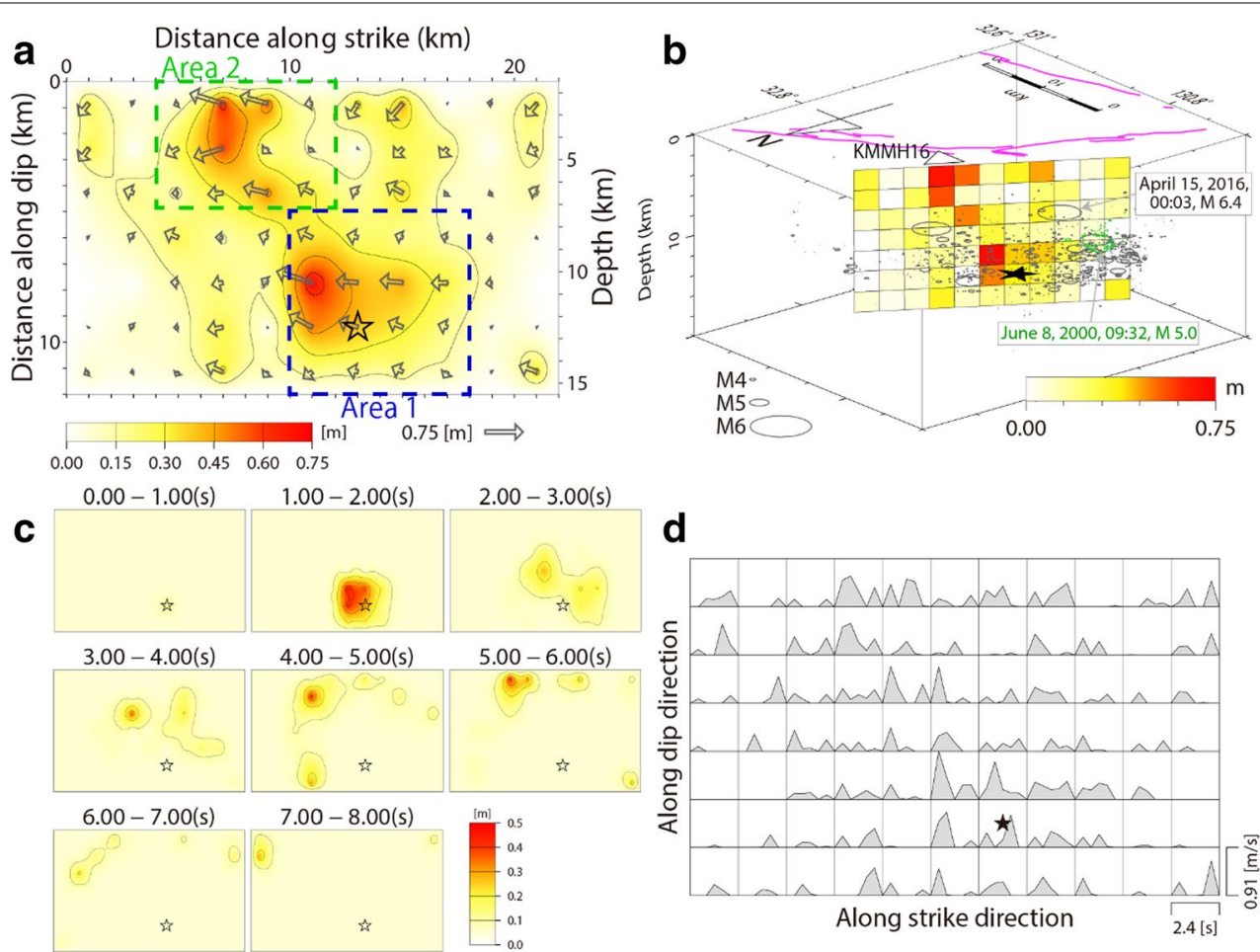

Fig. 8 a Total slip distribution of the M 6.5 event on the fault. Slip contour interval is $0.15 \mathrm{~m}$. The vectors denote the direction and the amount of the slip of the hanging wall side. The star denotes the rupture starting point. The rectangles with blue and green broken lines indicate the areas with large slips defined in this study, Areas 1 and 2, respectively. b Perspective illustration of the total slip distribution (azimuth: $310^{\circ}$, elevation: $20^{\circ}$ ). Gray circles denote the hypocenters of events $(M \geq 1)$, which were determined by the NIED Hi-net, in the period between the $M$ 6.5 event and the $M 7.3$ event. Green circles denote the hypocenters of events $(M \geq 1)$ from June 8, 2000, to September 8, 2000, as determined by JMA. Circle sizes indicate the event magnitudes. Open triangle denotes KiK-net KMMH16 station. c Rupture progression for the $\mathrm{M} 6.5$ event in terms of slip amount for each 1.0-s time window. Slip contour interval is $0.1 \mathrm{~m}$. d Slip-velocity time function of each subfault. The star denotes the subfault corresponding to the rupture starting subfault

Another region with large slips $(>1.6 \mathrm{~m})$ is found at the depth of 5-10 km above the rupture starting point. These slips were caused by a rupture at $2-6 \mathrm{~s}$ propagating toward the surface from the rupture starting point. After it reached the near surface, the rupture propagated toward the northeast along the near surface at 6-10 s with large slips. This rupture occurred on the Takano-Shirohata segment of the Hinagu fault zone and the southern part of the Futagawa segment of the Futagawa fault zone.

The field surveys discovered surface ruptures with a length of approximately $30 \mathrm{~km}$ along the surface traces of the Hinagu and Futagawa fault zones after the $M 7.3$ event (e.g., GSJ/AIST 2016; Kumahara et al. 2016; Shirahama et al. 2016). They reported that the surface ruptures near the epicenter were not very large $(<0.5 \mathrm{~m})$, and that large surface ruptures of more than $1 \mathrm{~m}$ were observed from approximately $5 \mathrm{~km}$ to approximately $30 \mathrm{~km}$ northeast of the epicenter along the Futagawa fault zone. The extent of the large near-surface slips in our source model (Fig. 4) is roughly consistent with the extent of the observed large surface ruptures.
Figure $4 \mathrm{a}, \mathrm{b}$ shows the hypocenter distribution of the aftershocks following the $M 7.3$ event. Most of the events are located deeper than $5 \mathrm{~km}$, and there are few aftershocks in the shallow part of the large slip region $(>2.4 \mathrm{~m})$. Some events do occur in the deep part of the large slip region, which includes the largest aftershock following the $M 7.3$ event (April 16, 2016, 01:45, JST; $M_{\text {JMA }}$ 5.9). The seismicity is high near the hypocenter and south of the hypocenter.

Pulido (2016) applied a seismic back-projection analysis (Pulido et al. 2008) to this event with strong-motion waveforms in the period of $5-10 \mathrm{~Hz}$. Based on his result, high-frequency seismic waves were radiated mainly from the region around the hypocenter. However, in our source model, the main rupture with large slips occurred more than $10 \mathrm{~km}$ northeast of the hypocenter, and the minor rupture occurred near the hypocenter (Figs. 4, 5a). This difference suggests the possibility that the seismic radiation of the $M 7.3$ event had a frequency-dependent spatial variation: The rupture near the hypocenter had modest slips and a strong high-frequency seismic 


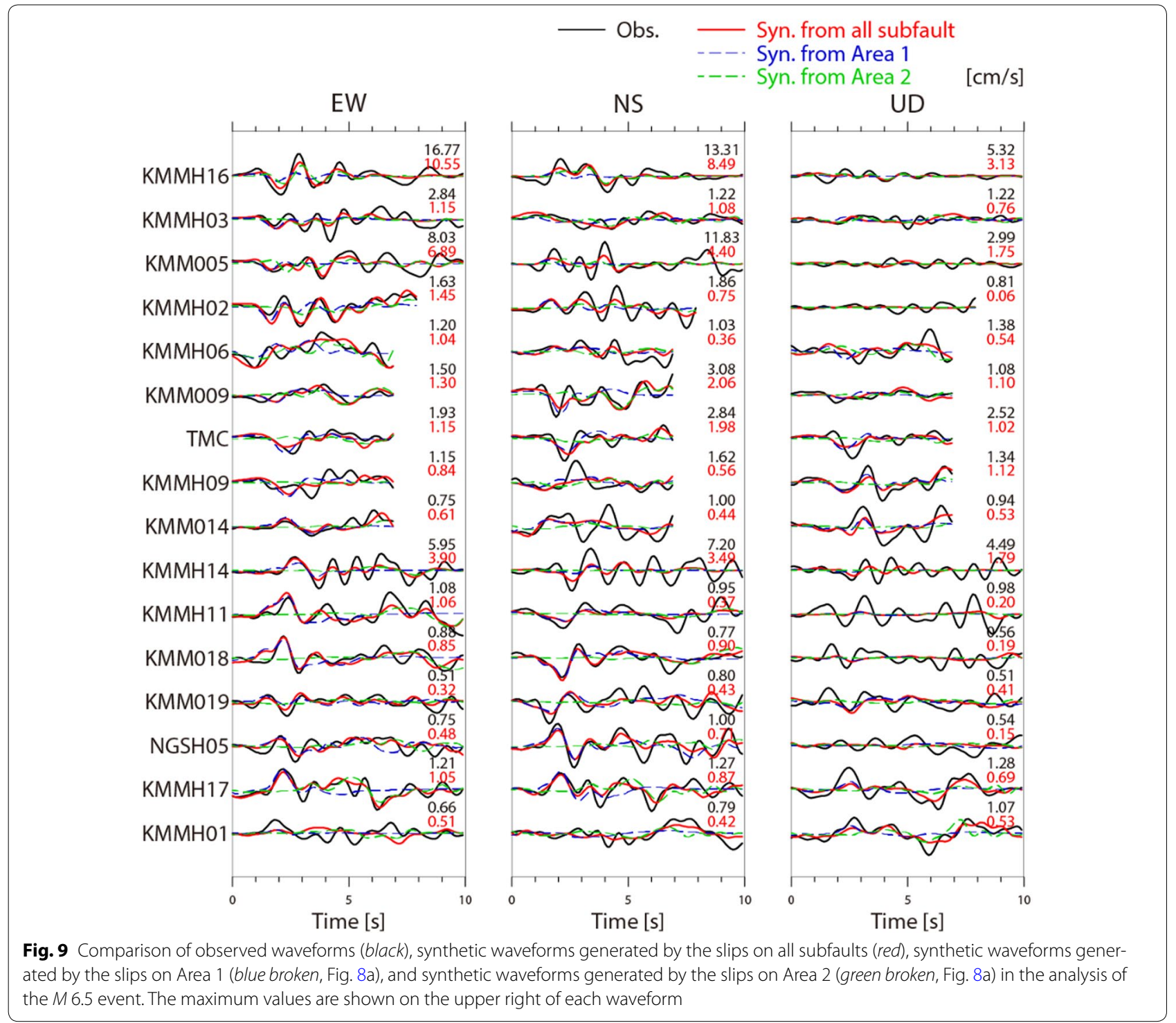

radiation, whereas the rupture $10-30 \mathrm{~km}$ northeast of the hypocenter had large slips and a weak high-frequency seismic radiation.

Figure 6 shows a comparison between the observed and the synthetic waveforms. The synthetic waveforms fit well the observations. Figure 7a shows the contribution of three fault areas (shown in Fig. 4c) to the synthetic waveforms at the near-fault stations. Area 1 includes the large slip area near the hypocenter, Area 2 corresponds to the near-surface rupture area at 6-10 s on the southern part of the Futagawa segment, and Area 3 corresponds to the large slip area $10-30 \mathrm{~km}$ northeast of the hypocenter with the maximum slip. The slips on Area 1 largely contributed the seismic waveforms at the stations south of the fault (e.g., KMMH14, KMMH09, and KMMH11). KMMH16 and KMM006, which are near the epicenter, had seismic intensities of 7 and 6-upper and PGAs of 1362 and $843 \mathrm{~cm} / \mathrm{s}^{2}$, respectively. The seismic waveforms at KMMH16 and KMM006 consisted mainly of contributions from the slips on Areas 1 and 2. The seismic waveforms that radiated from Area 3 are significant at many stations.

\section{The M 6.5 event (April 14, 2016, 21:26, JST)}

Fault model, method, and data

The source process of the $M 6.5$ event was estimated with almost the same methodology as that of the $M 7.3$ event. Hereafter, we mention only the differences from the analysis for the $M 7.3$ event. For the fault model, we assume a $22 \mathrm{~km} \times 14 \mathrm{~km}$ rectangular plane with a strike of $212^{\circ}$ and a dip of $89^{\circ}$ based on the F-net moment tensor solution. The rupture starting point is set at the hypocenter 
location, $32.7417^{\circ} \mathrm{N}, 130.7994^{\circ} \mathrm{E}$, and depth of $12.49 \mathrm{~km}$, determined in the same way as we did for the $M 7.3$ event. This near-vertical fault is consistent with the hypocenter distribution of events just after the $M 6.5$ event (Fig. 2c). The top depth of the fault model is approximately $1.5 \mathrm{~km}$; its extension to the surface corresponds to the surface trace of the Hinagu fault zone (Fig. 3b). This fault model corresponds to the Takano-Shirohata segment of the Hinagu fault zone. Although the $M 7.3$ event also had a rupture along the Takano-Shirohata segment of the Hinagu fault zone, the dip angle inferred from the hypocenter distribution differs between these events (Fig. 3c). The causative fault of the $M 6.5$ event is considered to differ spatially from that of the $M 7.3$ event on the Takano-Shirohata segment of the Hinagu fault zone.

The fault plane model is divided into 11 subfaults along the strike direction and 7 subfaults along the dip direction, each with a size of $2 \mathrm{~km} \times 2 \mathrm{~km}$. The slip time history of each subfault is represented by 5 time windows with a width of $0.8 \mathrm{~s}$, each with a lag of $0.4 \mathrm{~s}$. Thus, the allowed slip duration for each subfault is $2.4 \mathrm{~s}$. The central rake angle is set to $-164^{\circ}$, which is the rake angle of the F-net moment tensor solution.

We use three-component strong-motion waveforms at 16 stations within an epicenter distance of approximately $50 \mathrm{~km}: 5 \mathrm{~K}-\mathrm{NET}$ stations with ground surface observation, $8 \mathrm{KiK}$-net stations with borehole observation, 2 KiK-net stations with ground surface observation, and $1 \mathrm{~F}$-net station with observation in a vault (Fig. 3b). The velocity waveforms at these stations are band-pass filtered between 0.1 and $1.0 \mathrm{~Hz}$ and resampled to $10 \mathrm{~Hz}$. The time window of the observed waveforms begins at $1 \mathrm{~s}$ before the S-wave arrival, and its length for each station varies from 7 to $10 \mathrm{~s}$ to avoid the effect of the local event just after the $M 6.5$ event. For the station closest to the fault, KMMH16, we use a weight that is two times larger than those for the other stations

\section{Source process of the $M 6.5$ event}

Figure 8 shows the total slip distribution of the $M 6.5$ event by projection on fault (Fig. 8a) and perspective illustration (Fig. 8b), the rupture progression (Fig. 8c), and the slip-velocity time function of each subfault (Fig. 8d). The seismic moment and maximum slip are $1.7 \times 10^{18} \mathrm{Nm}\left(M_{\mathrm{w}} 6.1\right)$ and $0.7 \mathrm{~m}$, respectively. $V_{\mathrm{ftw}}$ is $2.5 \mathrm{~km} / \mathrm{s}$, which gives the smallest misfit solution among the solutions obtained using $V_{\mathrm{ftw}}$ ranging from 1.8 to $3.8 \mathrm{~km} / \mathrm{s}$. Large slips $(>0.4 \mathrm{~m})$ are found in the region around the rupture starting point and in the shallow region north-northeast of the rupture starting point; both region had a maximum slip of $0.7 \mathrm{~m}$. The ruptures in these regions occurred at $1-3 \mathrm{~s}$ and $3-6 \mathrm{~s}$ after rupture initiation, respectively. These slip values are smaller than those on the Takano-Shirohata segment of the Hinagu fault zone in the $M 7.3$ event $(>1 \mathrm{~m})$.

Figure $8 \mathrm{~b}$ also shows the hypocenter distribution of events in the period between the $M 6.5$ event and the $M 7.3$ event. Most events are located deeper than $5 \mathrm{~km}$; there are few aftershocks in the shallow large slip region. The seismicity in the large slip region around the hypocenter is relatively low compared to that in the surroundings. Many events, including the largest earthquake in the period (April 15, 2016, 00:03, JST; $M_{\mathrm{JMA}}$ 6.4), occurred north and south of the major slip region.

The $M_{\text {JMA }} 5.0$ earthquake (June 8, 2000, 09:32 JST) and the aftershocks had occurred near the source area of the $M 6.5$ event. These events were located south of the major rupture region of the $M 6.5$ event and within the southern part of the high-seismicity area after the $M 6.5$ event (Fig. 8b).

Kumahara et al. (2016) and Shirahama et al. (2016) reported that small surface cracks were observed by some residents along the Takano-Shirohata segment of the Hinagu fault zone just after the $M 6.5$ event. The occurrence of the near-surface large slips in our source model for the $M 6.5$ event is consistent with the appearance of the small surface cracks.

Figure 9 shows a comparison between the observed and synthetic waveforms. The synthetic waveforms reproduce the major features of the observed waveforms. Figure 9 also shows the contributions of two major rupture areas (Areas 1 and 2) to the synthetic waveforms. Area 1 includes the large slip area near the hypocenter, and Area 2 includes the shallow large slip area north-northeast of the hypocenter (Fig. 8a). At many stations, the slips in Area 1 contribute the most to the synthetic waveforms; the contribution of the slips in Area 2 is not very large. However, at KMMH16, which recorded seismic intensity of 6-upper and PGA of $1580 \mathrm{~cm} / \mathrm{s}^{2}$ during the $M$ 6.5 event, the contribution of the slips in Area 2 is also large because of the short distance between KMMH16 and Area 2 (Fig. 8b). Additionally, at KMMH16, the synthetic waveforms generated from Area 2 overlap those from Area 1 because KMMH16 is located in the forward direction of the rupture propagating from Area 1 to Area 2. This forward directivity is expected to have caused the strong ground motions at KMMH16 and its surroundings. The Mashiki town hall, which is close to KMMH16, recorded seismic intensity of 7 and PGA of $817 \mathrm{~cm} / \mathrm{s}^{2}$.

\section{Discussion}

For the $M 7.3$ event, we also conducted another source inversion using a single rectangular fault plane $56 \mathrm{~km} \times 24 \mathrm{~km}$ with a strike of $226^{\circ}$ and a dip of $65^{\circ}$ (Fig. 2a). The fault plane was divided into $2 \mathrm{~km} \times 2 \mathrm{~km}$ subfaults. The inversion settings, such as the station 
distribution and the smoothing constraint, were the same as for the analysis with the curved fault model. A comparison between the synthetic waveforms from the curved fault and the single fault plane models (Fig. 6) demonstrates that the use of the curved model leads to improved waveform fit at the stations south of the fault (KMMH14, KMMH11, SIB, and KMMH07). Figure 7b shows the observations and the synthetic waveforms radiated from the southern part of each fault model at KMMH14, KMMH11, SIB, and KMMH07. This figure indicates that the synthetic waveforms at these stations radiated were mainly from the southern part of each fault model and that the difference of synthetic waveforms at these stations shown in Fig. 6 is caused mainly by the fault geometry of the southern part. The stations of KMMH14, KMMH11, and SIB are located along the direction of the southwestern extension of the southern part of the curved fault model, that is, the maxima direction of S-wave radiation pattern of the right-lateral strike-slip fault. In contrast, the stations are not located along the maxima direction of S-wave radiation pattern in the case of the single fault plane model. This positional relationship between the stations and the curved fault model leads to improved waveform fit at these stations, demonstrating the importance of using a curved fault model for analysis of the $M 7.3$ event.

\section{Conclusions}

We estimated the source processes for two large events of the 2016 Kumamoto earthquakes (the $M 7.3$ event at 1:25 JST on April 16, 2016, and the $M 6.5$ event at 21:26 JST on April 14, 2016) from strong-motion waveforms. To analyze the source process of the $M 7.3$ event, we developed a realistic curved fault model. The source model for the M 7.3 event had two significant ruptures: One rupture with large slips propagated toward the direction of the northeastern shallow region at $4 \mathrm{~s}$ after rupture initiation and continued to approximately $16 \mathrm{~s}$. This rupture caused the large slip region with a peak of $3.8 \mathrm{~m}$ that is located $10-30 \mathrm{~km}$ northeast of the hypocenter and reached the caldera of Mt. Aso. There were few aftershocks in the shallow part of the large slip region, although some aftershocks occurred in the deep part. The contribution of the large slip region to the seismic waveforms was significant at many stations. The other rupture propagated toward the surface from the hypocenter at 2-6s and then propagated toward the northeast along the near surface at $6-10 \mathrm{~s}$. This rupture largely contributed the seismic waveforms at the stations south of the fault and close to the hypocenter. A comparison with the results obtained using a single fault plane model demonstrates that the use of the curved fault model led to improved waveform fit at the stations south of the fault. A comparison between our source model and a back-projection result with highfrequency seismic waves suggested the possibility that the seismic radiation of the $M 7.3$ event had a frequencydependent spatial variation. The source model obtained for the $M 6.5$ event had large slips in the region around the hypocenter and in the shallow region north-northeast of the hypocenter. Both regions had a maximum slip of $0.7 \mathrm{~m}$. The rupture of the $M 6.5$ event propagating from the hypocentral region to the region north-northeast could have caused the strong ground motions due to the forward directivity effect at KMMH16 and surroundings. The seismicity in the large slip areas of this earthquake was relatively low compared to that of the surroundings. The source-inversion results of this study were consistent with the field survey observations of surface ruptures. The source models estimated in this study are available at http://www.kyoshin.bosai.go.jp/inversion/.

\section{Authors' contributions}

HK analyzed the data, interpreted the results, and drafted the manuscript. WS also analyzed the data and interpreted the results. SA and HS participated in the design of the study and the interpretation of the results. All authors read and approved the final manuscript.

\section{Author details}

${ }^{1}$ National Research, Institute for Earth Science and Disaster Resilience, 3-1, Tennodai, Tsukuba, Ibaraki 305-0006, Japan. ${ }^{2}$ Disaster Prevention Research Institute, Kyoto University, Gokasho, Uji, Kyoto 611-0011, Japan.

\section{Acknowledgements}

We thank Prof. Ralph J Archuleta and the anonymous reviewer for their helpful comments. We used the unified hypocenter catalog determined by JMA and the 10-m mesh DEM published by the Geospatial Information Authority of Japan. We also used Generic Mapping Tools (Wessel and Smith 1998) to draw the figures.

\section{Competing interests}

The authors declare that they have no competing interests.

Received: 1 July 2016 Accepted: 19 September 2016

Published online: 03 October 2016

\section{References}

AIST (National Institute of Advanced Industrial Science and Technology) (2007) Active fault database of Japan, December 13, 2007 version. AIST, Tsukuba

Akaike H (1980) Likelihood and the Bayes procedure. In: Bernardo JM, DeGroot MH, Lindley DV, Smith AFM (eds) Bayesian statistics. University Press, Valencia, pp 143-166

Aoi S, Kunugi T, Nakamura H, Fujiwara H (2011) Deployment of new strong motion seismographs of K-NET and KiK-net. In: Akkar S, Gülkan P, van EckT (eds) Earthquake data in engineering seismology. Geotechnical, geological, and earthquake engineering, vol 14. Springer, Dordrecht, pp 167-186. doi:10.1007/978-94-007-0152-6_12

Bouchon M (1981) A simple method to calculate Green's function for elastic layered media. Bull Seismol Soc Am 71(4):959-971

ERC/HERP (Earthquake Research Committee/Headquarters for Earthquake Research Promotion) (2013) Elevation of the Futagawa fault zone and the Hinagu fault zone. February 1, 2013 version (partially revised). http:// www.jishin.go.jp/main/chousa/13feb_chi_kyushu/k_11.pdf. Accessed 17 June 2016 (in Japanese)

FDMA (Fire and Disaster Management Agency) (2016) The 2016 Kumamoto earthquake (78th report). http://www.fdma.go.jp/bn/2016/detail/960. html. Accessed 26 Sept 2016 (in Japanese) 
Fujiwara H, Kawai S, Aoi S, Morikawa N, Senna S, Kudo N, Ooi M, Hao KX, Hayakawa Y, Toyama N, Matsuyama H, Iwamoto K, Suzuki H, Liu Y (2009) A study on subsurface structure model for deep sedimentary layers of Japan for strong-motion evaluation. In: Technical note 337, National Research Institute for Earth Science and Disaster Prevention, Tsukuba, Japan (in Japanese)

Fukuyama E, Ishida M, Dreger DS, Kawai H (1998) Automated seismic moment tensor determination by using on-line broadband seismic waveforms. J Seismol Soc Jpn (Zisin 2) 51:149-156 (in Japanese with English

\section{abstract)}

GSJ/AIST (Geological Survey of Japan/National Institute of Advanced Industrial Science and Technology (2016) 4th report (May 3, 2016): emergency survey report for surface earthquake faults associated with the 2016 Kumamoto earthquake. https://www.gsj.jp/hazards/earthquake/kumamoto2016/kumamoto20160513-1.html. Accessed 17 June 2016 (in

\section{Japanese)}

Hartzell SH, Heaton T (1983) Inversion of strong ground motion and teleseismic waveform data for the fault rupture history of the 1979 Imperial Valley, California, earthquake. Bull Seismol Soc Am 73:1553-1583

Kennett BLN, Kerry NJ (1979) Seismic waves in a stratified half space. Geophys J R Astr Soc 57:557-583

Kumahara Y, Goto H, Nakata T, Ishiguro S, Ishimura D, Ishiyama T, Okada S, Kagohara K, Kashihara S, Kaneda H, Sugito N, Suzuki Y, Takenami D, Tanaka K, Tanaka T, Tsutsumi H, Toda S, Hirouchi D, Matsuta N, Mita T, Moriki H, Yoshida H, Watanabe M (2016) Distribution of surface rupture associated the 2016 Kumamoto earthquake and its significance. IN: Japan Geoscience Union Meeting 2016 MIS34-05

Lawson CL, Hanson RJ (1974) Solving least squares problems. Prentice-Hall, Old Tappan

Okada Y, Kasahara K, Hori S, Obara K, Sekiguchi S, Fujiwara H, Yamamoto A (2004) Recent progress of seismic observation networks in Japan: Hi-net, F-net, K-NET and KiK-net. Earth Planets Space 56:15-28

Olson AH, Apsel RJ (1982) Finite faults and inverse theory with applications to the 1979 Imperial Valley earthquake. Bull Seismol Soc Am 72:1969-2001

Ozawa T, Fujita E, Ueda H (2016) Crustal deformation associated with the 2016 Kumamoto Earthquake and its effect on the magma chamber of Aso volcano. In: Japan Geoscience Union Meeting 2016 MIS34-P42
Pulido N (2016) Rupture process of the April 16, 2016 Kumamoto earthquake (Mjma7.3) using seismic back-projection and K-NET/KiKnet waveforms. In: Japan Geoscience Union Meeting 2016 MIS34-P68

Pulido N, Aoi S, Fujiwara H (2008) Rupture process of the 2007 Notohanto earthquake by using an isochrones back-projection method and K-NET and KiK-net data. Earth Planets Space 60:1035-1040

Sekiguchi H, Irikura K, Iwata T (2000) Fault geometry at the rupture termination of the 1995 Hyogo-ken Nanbu earthquake. Bull Seismol Soc Am 90:117-133

Shirahama Y, Yoshimi M, Awata Y, Maruyama T, Azuma T, Miyashita Y, Mori H, Imanishi K, Takeda N, Ochi T, Otsubo M, Asahina D, Miyakawa A (2016) Characteristics of the surface ruptures associated with the 2016 Kumamoto earthquake sequence, Kyushu, southwestern Japan. In: Japan Geoscience Union Meeting 2016 MIS34-P45

Suzuki W, Aoi S, Sekiguchi H (2010) Rupture process of the 2008 Iwate-Miyagi Nairiku, Japan, earthquake derived from near-source strong-motion records. Bull Seismol Soc Am 100(1):256-266. doi:10.1785/0120090043

Wald DJ, Helmberger DV, Heaton TH (1991) Rupture model of the 1989 Loma Prieta earthquake from the inversion of strong-motion and broadband teleseismic data. Bull Seismol Soc Am 81:15401572

Waldhauser F, Ellsworth WL (2000) A double-difference earthquake location algorithm: method and application to the Northern Hayward fault. Bul Seismol Soc Am 90:1353-1368

Wessel P, Smith WHF (1998) New, improved version of Generic mapping tools released. EOS Trans Am geophys Union 79:579

Yano TE, Matsubara M (2016) The significance of seismicity after The 2016 Kumamoto Earthquake sequence. In: Japan Geoscience Union Meeting 2016 MIS34-P05

Yarai H, Kobayashi T, Morishita Y, Fujiwara S, Munekane H, Hiyama Y, Kawamoto S, Miyahara B, SAR Analysis Group, GEONET Analysis Group (2016) Crustal deformation of the 2016 Kumamoto Earthquake. In: Japan Geoscience Union Meeting 2016 MIS34-03

\section{Submit your manuscript to a SpringerOpen ${ }^{\circ}$ journal and benefit from:}

- Convenient online submission

- Rigorous peer review

- Immediate publication on acceptance

- Open access: articles freely available online

- High visibility within the field

- Retaining the copyright to your article

Submit your next manuscript at springeropen.com 